\title{
Research of mechanisms of transformation and removal of antibiotics from wine by sorbents of different nature
}

\author{
Mikhail Antonenko *, Tatiana Guguchkina, Olga Antonenko, Alla Abakumova, and Anton \\ Khrapov
}

Federal State Budget Scientific Institution «North Caucasian Federal Scientific Center of Horticulture, Viticulture, Wine-making», 39 str. 40 Let Pobedy, Krasnodar, 350901, Russia

\begin{abstract}
On the basis of own research, the authors experimentally confirmed the reliability of the hypothesis expressed in the scientific literature about the possibility of effective removal of nisin and natamycin from wines and wine materials. New knowledge has been obtained about the possible mechanisms of sorption of nisin and natamycin through the use of sorbents of various nature. Comparative experimental data on the interaction of sorbents with antibiotics in wines are presented. In this work, experimental data are presented that indicate different efficiency of antibiotic removal during wine processing, which is due to the structure and properties of sorbents. It has been shown that the sorption capacity of sorbents for natamycin and nisin decreases in the series: activated carbon, bentonite, and colloidal silicon dioxide. Mathematical models have been obtained for decontamination of antibiotics from wine production using sorbents of various nature.
\end{abstract}

\section{Introduction}

Food quality control is an integral part of the overall food safety system [1-6]. The methods and approaches used in the study to disclose the mechanisms of sorption and removal of antibiotics of microbial origin from wines to increase consumer safety and control the quality of wine products are comparable to the studies of foreign scientists [1-6].

Such studies include the work of Chinese scientists to improve the methods of analysis of antibiotic and to establish the efficiency of removing natamycin from wines by sorbents of various nature [2].

The identification of the mechanisms of sorption of antibiotics of microbial origin by sorbents of different nature, exhibiting different mechanisms of action, was carried out taking into account modern approaches to the physical chemistry of dispersed systems and colloidal phenomena in these systems, considering the current state and development trends in the field of sedimentation analysis.

\footnotetext{
* Corresponding author: antonenko84@,bk.ru
} 
The aim of this study was to evaluate and compare the interaction of bacteriocin nisin and fungicide of the polyene macrolide group of natamycin (pimaricin) with sorbents of various types.

Algorithms for the identification of food additives (preservatives and antibiotics of a microbial nature) in wine products are relevant for the production sector when using imported raw materials, as well as for ensuring consumer safety of alcoholic beverages $[5,6]$.

\section{Materials and methods}

To establish the effective adsorption capacity of sorbents to remove antibiotics of microbial origin from wine, a model system was used. It was a mixture of dry table white wine of the Chardonnay variety and antibiotics nisin (E234) and natamycin (E235) at a mass concentration of 25 and $50 \mathrm{mg} / \mathrm{dm}^{3}$, respectively. The amount of applied antibiotics was determined based on the analysis of literature data.

Colloidal silicon dioxide (highly dispersed silica «Polysorb» with a particle size of up to $0.09 \mathrm{~mm}$ ), activated carbon (vegetable coal with a specific surface area of about $1400 \mathrm{~m}^{2} / \mathrm{g}$ ) and bentonite (in the form of a suspension of bentonite clays containing no colloidal fraction no less than $80 \%$ ) were used as sorbents. The studied dosages of sorbents were 0.5 ; $1 ; 1.5$ and $2.0 \mathrm{~g} / \mathrm{dm}^{3}$.

Highly efficient capillary electrophoresis was used as the main analytical method for determining the residual amounts of antibiotics of microbial origin: (The authors used methods for the determination of natamycin (patent 2018102766/15 Method for the determination of natamycin by capillary electrophoresis) and nisin (a technique developed by scientists of the FSBSI NCFSCHVW: STO 00668034-086-2017 "Alcoholic and nonalcoholic beverages. Determination of nisin by capillary electrophoresis).

The sorption efficiency was assessed by the difference between the concentrations of antibiotics before and after treatment with sorbents at different dosages.

All determinations and tests were carried out in duplicate.

\section{Results and discussion}

It is known that activated vegetable carbon is an inert (odorless and tasteless) active carbon adsorbent for eliminating a number of defects in wine. Typically used to remove off-flavors in wort and wine, it is particularly effective for treating against moldy flavors, herbaceous flavors, and for decontaminating the mycotoxin ochratoxin A $[7,8,9]$.

The high efficiency of the sorption of antibiotics by activated carbon was established, at a dosage of $1 \mathrm{~g} / \mathrm{dm}^{3}-80 \%$ for nisin and $78 \%$ for natamycin. In our opinion, the high degree of removal of nisin and natamycin is associated with the high sorption capacity of activated carbon and its developed effective specific surface, capable of actively interacting with high molecular weight components of wine, including nisin and natamycin. With an increase in the dosage of the sorbent to $2 \mathrm{~g} / \mathrm{dm}^{3}$, the sorption efficiency remained at the level of $80 \%$, however, a strong discoloration was observed, which can negatively affect the color intensity of wines (Fig. 1).

Silicon dioxide ("Polysorb") is an inorganic non-selective polyfunctional sorbent that has pronounced sorption properties and binds toxic substances of various natures, including pathogenic bacteria and bacterial toxins, antigens, food allergens, drugs and poisons, heavy metal salts, radionuclides [11]. 


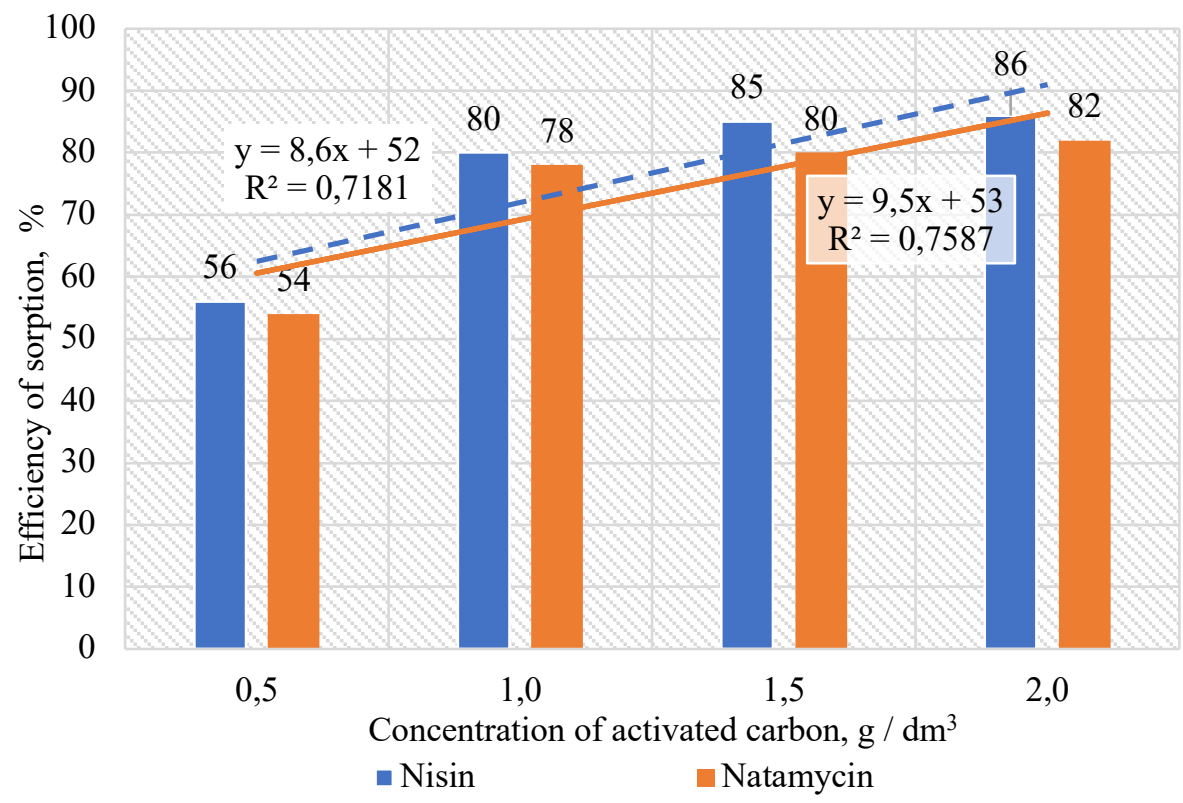

Fig. 1. Efficiency of sorption of antibiotics from wine depending on the mass concentration of activated carbon, $\%$

A linear dependence of the sorption of nisin and natamycin by an inorganic sorbent with colloidal silicon dioxide has been experimentally established. The sorption efficiency was low, and in the dosage range of $0.5-2.0 \mathrm{~g} / \mathrm{dm}^{3}$, it was $19-42 \%$, respectively (Fig. 2).

Bentonite is a natural montmorillonite with a high specific effective surface on which it interacts with substrates. Due to this fact, bentonite adsorbs proteins, polypeptides, amino acids, enzymes, yeast and bacterial cells [12,13, 14,Ошибка! Источник ссылки не найден.].




Fig. 2. Efficiency of sorption of antibiotics from the wine depending on the mass concentration of silicon dioxide, $\%$

The experimental results showed (Fig. 3) that bentonite has a high sorption capacity relative to nisin and natamycin. At a dosage of bentonite of $0.5 \mathrm{~g} / \mathrm{dm}^{3}$, more than $50 \%$ of the total concentration of antibiotics was removed. With an increase in the dose of bentonite to $2.0 \mathrm{~g} / \mathrm{dm}^{3}$, the removal efficiency was $80 \%$ for nisin and $75 \%$ for natamycin.

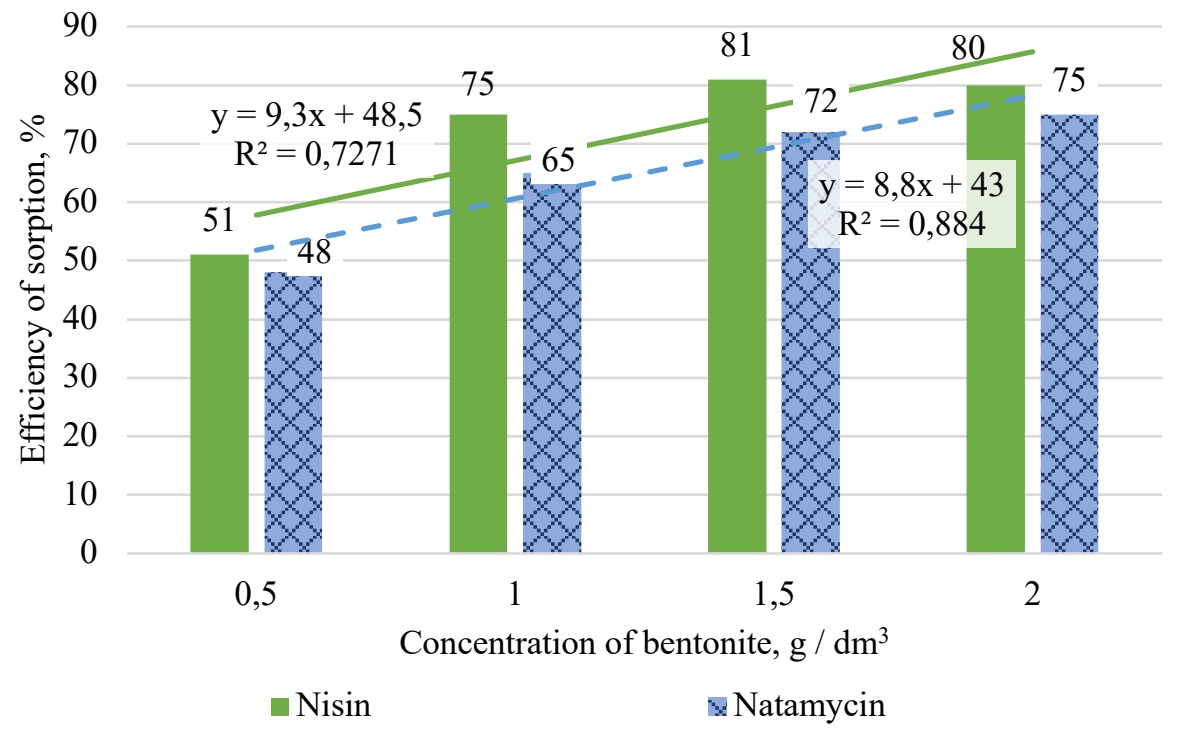

Fig. 3. Efficiency of sorption of antibiotics from the wine depending on the mass concentration of bentonite, $\%$

It is known that bentonite clays are traditionally used in winemaking practice to clarify and stabilize wine. Suspensions of bentonites contain at least $80 \%$ of the colloidal fraction, including amorphous silica, which leads to high adsorption properties. This allows not only to qualitatively clarify wine materials, but also to remove labile forms of high-molecular compounds into the sediment, to reduce the concentration of toxic compounds (including pesticides, toxins and even heavy metals).

In our opinion, the high sorption capacity of bentonite for the studied antibiotics of a microbial nature is explained by physical adsorption caused by the forces of intermolecular electrostatic interaction between the negatively charged surface of bentonite and the positive charge of nisin and natamycin.

Based on the results of the research, mathematical models for the decontamination of antibiotics from wines using sorbents of various natures are presented in the form of equations (table).

Table. Mathematical models (equations of dependence) for decontamination of antibiotics, where $\mathrm{y}$ - the sorption coefficient, $\mathrm{x}$ - the mass concentration of the sorbent,

$\mathrm{R}^{2}$ - the coefficient of determination

\begin{tabular}{|l|l|l|}
\hline \multirow{2}{*}{ Sorbent name } & \multicolumn{2}{|c|}{ Name of the antibiotic } \\
\cline { 2 - 3 } & \multicolumn{1}{|c|}{ Nisin } & Natamycin \\
\hline Activated carbon & $\mathrm{y}=8,6 \mathrm{x}+52 ; \mathrm{R}^{2}=0,7181$ & $\mathrm{y}=9,5 \mathrm{x}+53 ; \mathrm{R}^{2}=0,7587$ \\
\hline Silica & $\mathrm{y}=6,7 \mathrm{x}+13 ; \mathrm{R}^{2}=0,9899$ & $\mathrm{y}=6 \mathrm{x}+19 ; \mathrm{R}^{2}=0,9783$ \\
\hline
\end{tabular}




\begin{tabular}{|l|l|l|}
\hline Bentonite & $\mathrm{y}=9,3 \mathrm{x}+48,5 ; \mathrm{R}^{2}=0,7271$ & $\mathrm{y}=8,8 \mathrm{x}+43 ; \mathrm{R}^{2}=0,884$ \\
\hline
\end{tabular}

It follows from the table that with an increase in the value of $\mathrm{x}$ (mass concentration of the sorbent), the sorption efficiency, expressed by the value of $y$, also increases.

\section{Conclusion}

Theoretical approaches to the disclosure of the mechanisms of transformation and decontamination of antibiotics in wines have been substantiated and formulated.

Possible mechanisms of the sorption action of sorbents of different nature with respect to antibiotics of microbial origin (natamycin and nisin) are disclosed. The proposed interpretation of the mechanism of sorption of nisin and natamycin from wines is that their interaction is based on surface phenomena and is of a physical nature.

A hypothesis has been developed that the high sorption capacity of mineral sorbents for antibiotics of microbial origin is explained by the mechanisms of physical adsorption caused by the forces of intermolecular electrostatic interaction by the negatively charged surface of bentonite and the positive charge of nisin and natamycin, and not due to the adhesion forces that increase with decreasing particle size of the sorbent.

It is shown that the sorption capacity of sorbents for antibiotics decreases in the series: activated carbon, bentonite, and colloidal silicon dioxide.

As a result of the studies carried out on the removal of nisin and natamycin from wines by sorbents of various natures, mathematical models of antibiotic decontamination (in the form of linear equations) are presented.

Acknowledgments. The study was carried out with the financial support of the RFBR and the AKR in the framework of the scientific project No. 19-416-230067 p_a and partially in the framework of the fulfillment of the State task of the FSBSI NCFSCHVW

\section{References}

1. P. Alberts, M.A. Stander, A. de Villiers, S. Afr. J. Enol. Vitic., 32, 51-59 (2011) https://doi.org/10.21548/32-1-1366.

2. X. Sun, Food Chem., 194, 928-937 https://doi.org/10.1016/j.foodchem.2015.08.116.

3. J. F. Boelter, A. Brandelli, S. M. M. Meira, G. Göethel, S. C. Garcia, Appl. Cl. Sc., 188, 105490 (2020), https://doi.org/10.1016/i.clay.2020.105490.

4. N.A. Lopes, A. Brandelli, Critic. Rev. in Food Sc. and Nutr., 58, 13, 2202-2212 (2018) https://doi.org/10.1080/10408398.2017.1308915.

5. S.M.M. Meira, A.I. Jardim, A. Brandelli, FC, 188, 161-169 (2015). https://doi.org/10.1016/j.foodchem.2015.04.136.

6. T.H.H. Le, T.Q.H. Nguyen, C.S. Tran, T.T. Vu, T.L. Nguyen, V.H. Cao, T.D. Mai, FC, 77, 281-289 (2017) https://doi.org/10.1016/i.foodcont.2017.02.020.

7. Y. Yang, G. Li, D. Wu, J. Liu, X. Li, P. Luo, N. Hu, H. Wang, Y. Wu, Tr in Food Sc \& Tech, 96, 233-252 (2020), https://doi.org/10.1016/j.tifs.2019.12.021.

8. L. Filipe-Ribeiro, J. Milheiro, C. C. Matos, F. Cosme, F. M. Nunes, FC, 229, 242-251 (2017) https://doi.org/10.1016/i.foodchem.2017.02.066

9. F. Cosme, A. Inês, D. Silva, L. Filipe-Ribeiro, L. Abrunhosa, F. M. Nunes, LWT, 140, 110838, (2021) https://doi.org/10.1016/j.lwt.2020.110838.

10. L. Filipe-Ribeiro, J. Milheiro, C. C. Matos, F. Cosme, F. M. Nunes, Data in Brief, 12, 188-202 (2017) https://doi.org/10.1016/j.dib.2017.03.055. 
11. N. Casado, S. Morante-Zarcero, D. Perez-Quintanilla, J.S. Camara, I. Sierra, Tr. in Food Sc.e and Tech., 98, 167-180, (2020) https://doi.org/10.1016/j.tifs.2018.06.020 .

12. I. Arenas, M. Ribeiro, L. Filipe-Ribeiro, R. Vilamarim, E. Costa, J. Siopa, F. M. Nunes (2021), Foods, 10(3) https://doi.org/10.3390/foods10030608.

13. M. Jansson, S. Lenton, T.S. Plivelic, M. Skepö, J. of Coll.and Inter. Sc., 557, 767-776 (2019) https://doi.org/10.1016/j.jcis.2019.09.055.

14. M. V. Antonenko, T. I. Guguchkina, N. M. Ageeva, A. A. Abakumova, O. P. Antonenko // Fr. Grow. and vitic. in the South of Russia, 62 (2), 164-175 (2020) https://doi.org/10.30679/2219-5335-2020-2-62-164-175 (in Russian).

15. F. Cosme, A. Inês, B. Ferreira, D. Silva, L. Filipe-Ribeiro, L. Abrunhosa, F. M. Nunes, Foods, 9(12), 1789 (2020) https://doi.org/10.3390/foods9121789 